\title{
SUSTAINABLE UTILIZATION OF NATURAL RESOURCES IN CHINA
}

\section{G. D. Xie and C. X. Lu}

Institute of Geographical Sciences and Natural Resources Research, Chinese Academy of Sciences (CAS), P.R. China

Keywords: natural resources, water resources, land resources, marine resources, forests resources, mineral resources, biological resources, sustainable utilization of natural resources, management of natural resources

\section{Contents}

1. Introduction

2. Characteristics of Chinese Natural Resources

2.1 Land Resources

2.2 Water Resources

2.3. Climatic Resources

2.4. Biological Resources

2.5. Mineral Resources

2.6 Marine Resources

2.7 Energy Resources

3. Sustainable Utilization of Natural Resources

3.1. Establishing a Natural Resources Management System

3.2 Sustainable Utilization of Water Resources

3.3 Management and Sustainable Utilization of Land Resources

3.4 Sustainable Utilization of Forest Resources

3.5 Exploitation and Conservation of Marine Resources

3.6. Sustainable Utilization of Mineral Resources

3.7. Sustainable Production and Consumption of Energy Resource

Glossary

Bibliography

Biographical Sketches

\section{Summary}

This article stated the characteristics and current situations of Chinese natural resources and pointed out the problems arose from the exploitation, utilization, consumption and management of natural resources at present. In the meanwhile, this paper also introduced the countermeasures that China has taken on exploitation and utilization of water resource, land resource, biological resource and solar energy and so on for sustainable development.

\section{Introduction}

There are limits to the availability of natural resources for use by human beings, and therefore the problems of how natural resources can be allocated effectively and utilized rationally for generation after generation has become a fundamental issue for human 
society. In recent decades, humankind has realized that population, resources, environment and development problems are major threats to the future of humanity. There is "only one globe" and humanity shares a "common future". Economic growth is no longer the sole factor and humans now pay more attention to coordinated development among society_human and natural, and past, present and future. Humans have changed the mode of exploiting natural resources from "plundered utilization" to the strategic tracks of "permanent utilization" and "sustainable development".

China is in the process of industrialization and urbanization. But the conventional development pattern is seriously threatening the sustainable utilization of China's natural resources. Thus, the strategic choice for sustainable development is to pay lower social and resource costs but to reach a higher economic development level than the world average. This is a strategy for sustainable development with Chinese characteristics.

China is currently facing severe challenges in sustainable utilization and conservation of important resources, from two perspectives. First, China's share of resources per capita is low compared with world averages. In 1989, China's per capita share of resources such as freshwater, arable land, forest and grassland, comprised 28.1\%, 32.3\%, 14.3\% and $32.3 \%$ of the world averages respectively. Furthermore China's per capita resources have been declining continuously and ecological quality has worsened rapidly. Secondly, with the rapid population growth and excessive demands on natural resources for economic development, natural resources are becoming important limitations for social and economic development. According to the statistics, daily water shortage in China amounts to more than 16000000 ton and the consequent reduction of grain output is 2500000 tons per annum. Due to the shortage of water, industrial and agricultural production, as well as day-today lives of people, are seriously constrained. As things are at the moment, there are a number of problems concerning China's use and conservation of natural resources:

- Lack of effective integrated management of natural resources and lack of any mechanism for bringing natural resources accounting into national economic accounting; the traditional management model and legal system is facing the challenge of market economy.

- Traditional economic development relied too heavily on input of natural resources and energy, associated with wasted resources and output of pollution, and neglected the relationship between over-exploitation of natural resource and degradation of the natural environment.

- Inappropriate administrative intervention in access to natural resources; this seriously impeded effective allocation of resources, the establishment of a property right system and development of a free market in natural resources.

- Irrational methods of resource assessment caused the distortion of market prices, unpriced natural resources, or excessively high prices for resources and high demand.

- Absence of any mechanism for effective analysis of natural resource policy and lack of support for decisive information provision; in particular there is a serious lack of interdepartmental policy analysis and common sharing of information. Consequently there are often conflicts between different departments over natural 
resource policies.

- Lack of natural resources management mechanisms and institutions, causing divergence between organizations and lack of integrated management.

In order to allow the supply of natural resources to meet the rapidly expanding development of the economy, China must implement a series of policies such as "Protection, conservation and rational utilization of natural resources", and "Pay equal attention to exploitation and utilization, and conservation and proliferation". It is imperative to tap the potentiality of natural resources, depending on the progress of science and technology. It is also important to allocate resources effectively and to adhere to the principles of increasing utilization efficiency and development of a thrifty-type of economy based on market mechanisms and economic means. Resource exploitation and resource protection must go hand-in-hand with economic development.

\section{Characteristics of Chinese natural resources}

China has a vast territory and abundant resources with good natural conditions. In general, China has many advantages in terms of resource availability and potential for further exploitation and utilization. On the other hand, however, China's resources are relatively deficient in two respects: (a) shortage of resources per capita, and (b) Regionally unfavorable natural conditions, with an unbalanced economy in parts of the country, and past inappropriate exploitation of natural resources. This had unfortunate impacts on the natural ecology and created many environmental problems.

\subsection{Land Resources}

The total land area of China is very large and it has a favorable geographical position. China has a vast territory of $96000000 \mathrm{~km}^{2}$, which makes up one-fifteenth of the total land area of the earth. It has the third largest land area of the countries of the world. As the basic resource for human survival and wealth creation, the vast territory provides the means for developing various productive and constructive projects. Furthermore, the vast land area helps to overcome local deficiencies of resources by acquiring from other regions and utilizing each other's assets. Even if major natural disasters occurred they would never cause nationwide damage.

Usable land and special arable land is insufficient. The total land area amounts to 960000000 ha, of which about $60 \%$ is usable and occupied. Arable land is about 137000000 ha, about 14\% the total land area. Arable land area per capita is 0.13 ha, equivalent to one-sixth of that in USA. It is inevitable that some good farmland will be converted to other uses in the future and certainly other areas of poor farmland will be taken out of farming. The reclaimable marginal land is limited and there is no doubt that the area of arable land in China will decrease continuously.

The efficiency of land utilization is low and much farmland is of poor quality. The forestland makes up 30\% of the total arable land, of which the sparse woodland and clearance land occupies about $40 \%$. Although the grassland area is $40 \%$ of the total available land area, the grassland has a lower carrying capacity and its productivity is also lower than that in developed countries, providing poor yields of livestock products. Arable farmland makes up $23 \%$ of the total, of which the barren slop lands, 
water-logging lowland and saline or alkaline land occupies more than one-third. The reasons for these phenomena are not only the natural conditions but also the past extensive cultivation and poor management.

\subsection{Water Resources}

China has abundant water resources but water per capita of water is scarce. China receives a total average annual precipitation of $6 \times 10^{12} \mathrm{~m}^{3}$, which places it in sixth place for the countries of the world. Only about $45 \%$ of this total contributes to river runoff and groundwater recharge, the remainder being lost through evaporation. The total volume of freshwater resources available in China is therefore $2.8 \times 10^{12} \mathrm{~m}^{3} / \mathrm{a}$. Water resources per unit area in China is twice that of Africa and, is about the average level of Asia, Europe and North America, but it is much lower than South America and the western Pacific countries. In relation to the population, China has a low level of water resources, at $2700 \mathrm{~m}^{3}$ per capita per annum, which is one-fourth of the average level for the population of the Earth.

The distribution of precipitation in space and time vary greatly across China. Precipitation between years and at different seasons of the year are extremely variable, and this greatly decreases the water resources usability rate and can lead to drought, flood and water-logging disasters. The regional distribution of precipitation is characterized by more rainfall in the east than the west and more in the south than the north. Northern China includes important cities, such as Beijing, Tianjing, Shengyang, Dalian, and Qingdao; these have all experienced very serious water shortages in recent years. The misfit between supply and demand of water is becoming increasingly acute, and this retards social and economic development and improvement of living standards.

\subsection{Climatic Resources}

China has a warm climate and sufficient photothermal conditions. China lies in the middle latitude zones of the northern hemisphere and most parts belong to the temperate and subtropics zones which receive good sunlight and thermal conditions. Humid and semi-humid areas occupy half of the country, and the rain and high temperatures tend to occur in the same season, thus favoring rapid growth of plants and associated organisms. Because of the vast area, diversified landform and variety of climate types, China supports a huge variety of habitats and range of wild plants and animals. This favors the cultivation of plants from around the world, most of which can find suitable growth conditions somewhere in China.

Most regions of China have a continental climate with significant monsoon effects, and natural disasters are frequent occurrences. The northwest region, covering about $50 \%$ of the total area of China, receives less than $400 \mathrm{~mm}$ of annual precipitation. This is insufficient to meet the needs of normal growth of plants, and therefore agricultural production has to rely on irrigation. Because of the instability of the monsoon, precipitation is unevenly distributed in time and space, and there is a great difference of temperature between winter and summer. Precipitation and temperature are changeable and relatively unpredictable, and there are frequent natural disasters such as flooding and water-logging, drought, windstorms (typhoons and hot dry winds), low 
temperatures (freezing conditions, ice and frost), and hailstorms.

\subsection{Biological Resources}

Natural biota depend on and reflect the natural conditions of geology, soil, water and climate, and their combination and interaction. China has abundant biological resources including a great variety and species of wild animals, plants, cultivated plants and domestic animals. By developing its agriculture and exploiting and utilizing its biological resources China has proved that it can support its large human population — $20 \%$ of the world population—although it only has about $10 \%$ of the world's arable land.

There are many problems in the processes of exploiting and utilizing biological resources. There has been marked ecological deterioration caused by long-term deforestation, over-cultivation and the heavy damage to natural vegetation. At present forest coverage is about $12 \%$ (the world average is $30 \%$ ). As a kind of living regenerated resources, the biological resource should only be developed in favorable environments. Forests represent a climax ecosystem and its reduction and disappearance cause massive loss of biodiversity, including deterioration of the quality of the remaining fragments, change of micro-climates, and loss of vital habitat for wild animals. Deforestation also has massive implications for the conservation of water resources - impacting both quality and quantity of freshwater, as well as leading to soil erosion and land desertification.

\section{TO ACCESS ALL THE 14 PAGES OF THIS CHAPTER, Visit: http://www.eolss.net/Eolss-sampleAllChapter.aspx}

\section{Bibliography}

Chinese Government. (1994). China's Agenda For 21'st Century [in Chinese]. 191pp. China Environmental Science Press. [This is the white paper on China's population, environment and development.]

Robert Perlack, Milton Russel, and Shen Zh. M. (1993). Reducing greenhouse gas emission in China: institutional, legal, and cultural constraints and opportunities. Globe Environment Change, Vol.3, No.1, p81-82 [in English]. [This is the paper on China's current situation for greenhouse gas reduction].

State Statistical Bureau of China (1998). China Statistical Yearbook in 1997 [in Chinese]. 850pp. China Statistical Publishing House. [This provides China's social, economic statistics in 1997].

Zhang K.M (1990). The past, present, and future of environmental protection in China, the American Asian Review,Vol.8, No.2, [in Chinese]. [This reviews the environmental protection of China].

\section{Biographical Sketches}


Gao-Di Xie Ph. D. is a Professor at the Institute of Geographical Sciences and Natural Resources Research, Chinese Academy of Sciences, and Vice-chief director of the Chinese Disaster Prevention and Reduction Society, under the Chinese Resource Society. His main research fields include natural resources, ecology, and safety of resources and environment.

Chun-xia Lu, Ph.D., is a researcher in the Institute of Geographical Sciences and Natural Resources Research, Chinese Academy of Sciences. Her main research fields include environment impact assessment, natural resources, and agricultural ecology. 